Transportation Research Forum

Operational and Safety Evaluation of Freeways with Posted Minimum Speed Limit Author(s): Victor Muchuruza and Renatus Mussa

Source: Journal of the Transportation Research Forum, Vol. 44, No. 3 (Fall 2005), pp. 5-17

Published by: Transportation Research Forum

Stable URL: http://www.trforum.org/journal

The Transportation Research Forum, founded in 1958, is an independent, nonprofit organization of transportation professionals who conduct, use, and benefit from research. Its purpose is to provide an impartial meeting ground for carriers, shippers, government officials, consultants, university researchers, suppliers, and others seeking exchange of information and ideas related to both passenger and freight transportation. More information on the Transportation Research Forum can be found on the Web at www.trforum.org. 


\section{Operational and Safety Evaluation of Freeways with Posted Minimum Speed Limit}

An operational and safety evaluation was conducted in relation to the posting of the minimum speed limit of $40 \mathrm{mph}$ and the maximum speed limit of $70 \mathrm{mph}$ on the Florida rural interstate freeway system. The results showed that $57 \%$ of the recorded vehicles exceeded the maximum speed limit. Additionally, while only $0.14 \%$ of recorded vehicles had speeds below the $40 \mathrm{mph}$ posted minimum speed limit, 9\% of crash-involved vehicles were estimated to have speeds below 40 mph. The overrepresentation of slow-moving vehicles in the crash data suggests that even a small proportion of under-40-mph vehicles can have negative implications on safety. Thus, regulation of vehicle speeds at the lower end of the speed distribution is equally important. The second order polynomial model developed to estimate the risk of a vehicle being involved in a crash as a function of the speed deviation from the mean speed of traffic indicated that the minimum risk occurred when the driving speed was 8 mph above the mean speed, equal to the $85^{\text {th }}$ percentile speed observed in the field. Further, the Poisson regression modeling indicated that the difference between the $85^{\text {th }}$ and $15^{\text {th }}$ percentile speeds had a positive effect on crashes.

\section{by Victor Muchuruza and Renatus Mussa}

\section{INTRODUCTION}

Interstate highways are designed for high-speed mobility. Thus, the combination of excessively slow and fast-moving vehicles in a traffic stream creates unsafe operating conditions. The desire to have uniform traffic flow has led to the practice of regulating both minimum and maximum speed limits on freeways, particularly on rural interstate freeways. It is generally accepted that if a traffic stream is composed of a significant number of slowmoving vehicles then the number of passing and overtaking maneuvers is expected to be high. A high number of passing and overtaking maneuvers increases the likelihood of conflicts and crashes. Slow-moving vehicles also have the effect of reducing freeway throughput as they create a platoon of vehicles behind them.

Florida currently has a maximum speed limit of $70 \mathrm{mph}$ and a minimum speed limit of $40 \mathrm{mph}$ on rural interstate highways. It seems logical to question the safety of such a wide gap (30 mph) between the two speed limits suggesting an examination of safety and traffic-operating characteristics on these road sections. It can be assumed that a wide gap between maximum and minimum speed limits might be creating a number of negative effects associated with large speed differentials which include an increase in passing maneuvers and its attendant consequences of improper lane changing, tailgating (driving too close to the slow vehicle in front), frustrations of fast drivers, and formation of platoons of traffic.

Because the posting of minimum speed limits on highways has been motivated by the desire to regulate vehicle operating speeds to be as uniform as is practicable, this paper reviews the operational and safety issues in relation to the posting of these limits on Florida interstate highways. Of interest in the review are vehicle operating speeds at the lower end of the speed distribution, vehicle speed variations, and their contribution to the occurrence of traffic crashes. The following section reviews the literature related to the effect of speed variations and the posting of minimum speed limit. The next sections describe the research method used to conduct this study, followed by data analysis and finishing with the conclusion. 


\section{PREVIOUS STUDIES}

A positive correlation between speed variation in a traffic stream and crashes has been documented in numerous studies. Solomon (1964) showed a link between deviation from the mean speed and frequency of crashes. The author examined crash reports involving nearly 10,000 drivers on 35 sections of rural highways in 11 states. Upon comparing the deviation of the pre-crash speeds from the mean speed and the number of vehicles involved in the crash, Solomon (1964) found that the relationship between crashes and travel speed was a U-shaped parabolic curve in which vehicles that were traveling faster or slower than the mean speed had high crash involvement rates. The results of Solomon's study were supported by the results of a study conducted by Cirrilo (1968). Cirrilo analyzed crashes occurring on both rural and urban sections of interstate highways in 20 states. The author found that the crash involvement risk was highest for the vehicles traveling about 32 mph below the mean speed, falling to a minimum for vehicles traveling around $12 \mathrm{mph}$ above the mean speed, and then rising moderately with further increase of the speed above the mean. It is also worth noting that Harkey et al. (1990) recently replicated the Ushape relationship between vehicle travel speed and crash involvement rate using data collected in mostly built-up areas of Colorado and North Carolina roadways where the minimum risk was found to be about $90^{\text {th }}$ percentile speeds - $90 \%$ of the drivers are traveling below this speed.

Lave (1985) showed that the reduction of speed variance rather than average speed was the significant cause for the decline of fatality rates after the imposition of the national maximum speed limit of $55 \mathrm{mph}$ on interstate highways in 1974. The author indicated that the speed reduction was associated with a significant decrease in the spread of vehicle speeds at the higher end of the distribution and thus contracting the overall speed distribution. Later, results published by Garber and Gadiraju (1998) also support the prior findings that the frequency of crashes increases with the increase in speed variance. In addition, Garber \& Ehrhart (2000) have indicated that in low traffic volume conditions, the crash rate increases with the standard deviation of speeds while at relatively high traffic volume conditions, the crash rate decreases with standard deviation of speeds. The modeling of crashes has also shown that speed variance was statistically significant in affecting fatality rates. Data analyzed by the Transportation Research Board (1984) revealed states that had wider variances in speed tended to have higher fatality rates.

To mitigate the effect of slow driving on freeway safety, earlier research studies suggested either the use of posted minimum speed limit signs or the posting of median speed driving advisory signs on the highways to reduce speed variability (Harkey et al. 1990, West and Dunn 1978, and Hauer 1971). Hauer (1971) further suggested the introduction of driver education to inform the driving community that the risk of crashing is smallest in the vicinity of the median speed of the traffic stream and slow drivers are as much of a hazard as fast ones.

\section{METHODOLOGY}

The effect of the existing minimum speed limit can be evaluated through a study where both operational and traffic crash data are collected for similar sites with and without the minimum speed posted. Because all interstate highways in Florida have a minimum speed limit, conducting such a study would require creating experimental highway sections with $40 \mathrm{mph}$ minimum speed signs removed or covered. However, creating such sites has legal implications which are difficult to overcome at this time. Therefore, the research reported herein was limited to reviewing the operational and safety characteristics on the Florida rural interstate freeway system in relation to the posting of maximum and minimum speed limits. Of interest in the review was the operating speeds at the lower end of the speed distribution and the speed variances resulting from them. The safety review was focused on the analysis of crashes in terms of speed and crash-type occurrences that might be associated with the difference in speeds among the involved vehicles. The research efforts were also directed at conducting a regression analysis to determine the relationship between speed and 
frequency of crashes while testing a number of hypotheses related to the speed distribution.

\section{DATA COLLECTION}

Data were collected on rural sections of the Florida interstate highway system as well as on the Florida Turnpike, which is a tollway connecting central Florida to south Florida. As indicated earlier, all of these limited-access highways have speed limits of $70 \mathrm{mph}$ and $40 \mathrm{mph}$. Site selection criteria were based on the Florida Department of Transportation (FDOT) speed zoning manual (FDOT 1997). The manual requires choosing sites where the geometric characteristics of the road produce the highest free-flow speed possible. These are sites that are devoid of horizontal and vertical curves, sustained grades, or any other geometric constraints. In addition, the site selected had to have a telemetered traffic monitoring site (TTMS) in the vicinity. The TTMS is a permanent count station installed on a highway to collect continuous vehicle data. These sites are maintained by the Florida Department of Transportation Planning Office. Each TTMS site is equipped with loop detectors and an automatic data recorder which records vehicles' time of passage, speed, length, class, and lane of passage. After screening of about 70 TTMS sites located on Florida interstate highways, seven sites were selected. Of these seven sites, two were located on sections having six-lanes (three in each direction) and five were located on four-lane sections (two lanes in each direction).

Following the selection of the study sites, individual vehicle records were acquired for 24 hours on a typical weekday in good weather and dry pavement conditions. The analysis was limited to dry conditions because of the criteria of the Florida speed zoning manual (FDOT 1997). A customized computer program was written to extract volume and speed data from the individual records file. Erroneous data and other anomalies in the data samples were identified and removed to ensure integrity of the data. However, if erroneous data were too extensive for a particular day, another day's worth of data was downloaded from the respective telemetered traffic monitoring site.
Data for more than 350,000 vehicles were verified to be error-free and used to analyze traffic operations.

The next step in the research was to acquire data on traffic crashes. To have a sufficient sample size that represents crashes which occur on these highway sections, four-year crash data were acquired. The crash data were collected from January 1, 1998, to December 31 , 2001, by two-mile segment length on each site. The source of crash information was the Safety Office of the Florida Department of Transportation which maintains the hard copies of police reports written for crashes that occur on the state-maintained highway system. A total of 169 crashes were reported in these sections in the four-year analysis period. Crash attributes of interest were the severity level, type of crash, and the estimated pre-crash speed of involved vehicles.

\section{SPEED CHARACTERISTICS}

Analysis of speed characteristics involved examination of several statistics that describe measures of central tendency of the speed data and variations of vehicles speeds in the traffic stream. The measures of central tendency analyzed were $85^{\text {th }}$ percentile speed ( $85 \%$ of the vehicles are traveling below this speed), average speed, and $15^{\text {th }}$ percentile speed $(15 \%$ of the vehicles are traveling below this speed). The measures used to analyze speed variations were the standard deviation of speeds, coefficient of variation of speeds and the 10-mph pace speed. The coefficient of variation of speeds which measure the relative dispersion of vehicles speeds is calculated as the ratio of the standard deviation to the mean speed. The 10 -mph pace is the $10 \mathrm{mph}$ speed range with the highest number of observations of vehicles in the speed distribution.

Table 1 shows the results of the analysis of the speed characteristics. The results indicated that the level of service in most of these sections is $\mathrm{B}$ or better. Higher operating speeds are generally attainable at level of service (LOS) A and continually decrease as the speed-volume relationship moves towards congested flow conditions. LOS is a stratification of the quality of operation of the roadway from A through 
Table 1: Summary of Speed Statistics

\begin{tabular}{|l|c|c|}
\hline Statistic & four-lane sections & six-lane sections \\
\hline Level of service & $\mathrm{A}$ & $\mathrm{B}$ \\
\hline $15^{\text {th }}$ percentile speed (mph) & 67 & 65 \\
\hline Average speed (mph) & 73 & 73 \\
\hline $85^{\text {th }}$ percentile speed (mph) & 80 & 80 \\
\hline Pace speed (mph) & $69-79$ & $69-79$ \\
\hline Percent traveling in pace & 65 & 66 \\
\hline Standard deviation of speed (mph) & 6.2 & 5.4 \\
\hline Coefficient of variation of speed & 8.5 & 6.8 \\
\hline Percent traveling above $70 \mathrm{mph}$ & 56 & 57 \\
\hline Percent traveling below $40 \mathrm{mph}$ & 0.18 & 0.10 \\
\hline
\end{tabular}

$\mathrm{F}$ with "A" representing the most favorable driving conditions and " $F$ " the worst, measured at the peak hour period of the day (USDOT 2000). It is clear that the operating speeds on the sample highway sections are expected to be high because of low traffic interactions, and the speed variances resulting from high-speed operations might be a concern.

The speed analysis further showed that on the average, the mean speed of all vehicles on these sections was $73 \mathrm{mph}$, which is 3 mph above the posted maximum speed limit. Specifically, the percentages of vehicles exceeding the maximum speed limit were 56\% and $57 \%$ on four-lane and six-lane sections, respectively. The average speeds on four-lane sections ranged from $66 \mathrm{mph}$ to $74 \mathrm{mph}$, and 67 mph to $85 \mathrm{mph}$ on the shoulder (outer most) and the median lanes (inner most), respectively. On the six-lane sections, the average speeds of the vehicles on the shoulder, middle, and median lanes ranged from $67 \mathrm{mph}$ to $70 \mathrm{mph}, 72 \mathrm{mph}$ to $75 \mathrm{mph}$, and $75 \mathrm{mph}$ to $81 \mathrm{mph}$, respectively.

The analysis of speed data collected at these sites further showed that the $15^{\text {th }}$ percentile speed-which some engineering texts (McShane et al. 1998) suggests as the measure of slow driving-was $61 \mathrm{mph}$ to $77 \mathrm{mph}$ depending on the lane of travel-i.e., median (inner most) lanes had higher $15^{\text {th }}$ percentile speeds than shoulder lanes. The average of the $15^{\text {th }}$ percentile speeds across all sites was $65 \mathrm{mph}$. Table 1 further shows that only $0.18 \%$ and $0.10 \%$ of the vehicles had speeds below the posted minimum speed limit (40 mph) on fourlane and six-lane sections, respectively. The review of individual vehicle records did not reveal which types of vehicles predominate at the low end of the speed distribution. This is because the automatic data recorders in the field don't accurately classify recreational vehicles and vehicles that tow trailers. It is these types of vehicles that were casually observed in the field to be traveling at speeds below $55 \mathrm{mph}$. In terms of lane usage, this analysis showed that on both six-lane and four-lane sections most of the slow vehicles used the shoulder lane in conformance with Florida law requiring slow vehicles to use shoulder lanes.

The examination of the standard deviation of vehicle traveling speeds showed a minimum of $4 \mathrm{mph}$ to a maximum of $10 \mathrm{mph}$. The average standard deviations of speeds were $6.2 \mathrm{mph}$ and $5.4 \mathrm{mph}$ on four-lane and six-lane sections, respectively. The results further showed that the coefficient of variations were between $5 \%$ and $14 \%$. The comparison of the coefficient of variations between adjacent lanes on each site showed that the differences were less than $3 \%$. These results indicate that the dispersion of the vehicle speeds from the mean speed is relatively small thus indicating the sufficient uniformity of traffic flow in these sections. Further examination of speed characteristics indicated that the pace speed was between 69 mph and $79 \mathrm{mph}$. About two thirds of recorded vehicles were traveling in this speed range. 


\section{CRASH CHARACTERISTICS}

\section{Crash Types}

Of the 169 crashes that occurred on these sections in the four-year period, eight (4.7\%) were fatal crashes, $99(58.6 \%)$ were injury crashes, and $62(36.7 \%)$ were property damage only (PDO) crashes. Four major types of crashes were frequently reported in the crash forms - hit a roadside object and ran-off road, rear-end crashes, angle/sideswipe crashes, and overturned vehicles. Two crash types - rearend and sideswipe/angle - were of particular interest for further analysis given that one study suggested that these crash types are mostly associated with speed differentials between vehicles in the traffic stream (Gaber and Gadiraju 1998). Figure 1 shows the pictorial stratification of crashes by type. It can be deduced from Figure 1 that about 41\% of the total crashes involved a vehicle hitting a roadside object or a vehicle ran off the road. The rear-end and sideswipe crashes were the second and third most-occurring crashes, respectively. All other crash types accounted for $12 \%$ of the crashes and are categorized as other. were extracted from the crash report forms. Figure 2 shows the distribution of the estimated speed of vehicles before crash. In addition, the cumulative distribution of actual speed of the vehicles recorded from the permanent count stations is superimposed on the figure in $5 \mathrm{mph}$ increments because crash speeds are estimated to the nearest $5 \mathrm{mph}$. Comparison of the two distributions shows that the estimated traveling speed of the vehicle prior to the crash is skewed to the left of the actual vehicle speeds collected at the site.

Looking at the 10-mph speed range with the highest number of crashes for the curve representing estimated pre-crash speeds in Figure 2, it is observed that the majority of the vehicles involved in the crashes were traveling with estimated speed between $60 \mathrm{mph}$ and 70 $\mathrm{mph}$. This $60 \mathrm{mph}$ to $70 \mathrm{mph}$ speed range encompasses $66 \%$ of the vehicles reported to be involved in crashes. However, the curve representing actual field data of vehicle speeds shows that the majority of the vehicles, as defined by the pace, were traveling between 69 mph and $79 \mathrm{mph}$. At the lower end of the speed distribution, the results presented in Figure 2 show an over-involvement of low-speed

Figure 1: Distribution of Crash Types

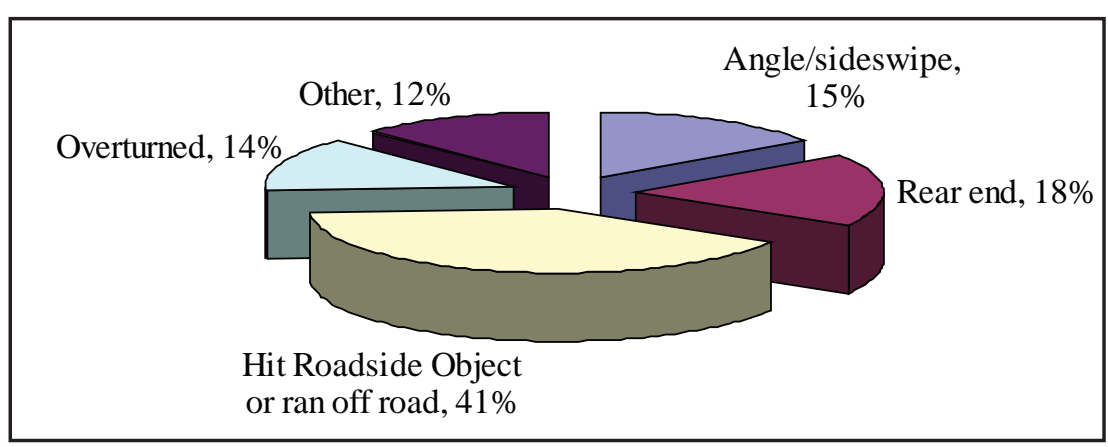

\section{Speed of Crash Involvement}

The speed of crash involvement is defined as the estimated vehicle speed when the crash occurred. The responding police officer to the crash scene generally estimates a vehicle speed using accident reconstruction techniques involving measuring skid marks and the degree of vehicle damage. The estimated vehicle speeds of the 244 vehicles involved in crashes vehicles. For example, the percent of vehicles involved in the crashes with estimated speeds below $55 \mathrm{mph}$ was significantly higher than the overall percent of vehicles observed in the field to be traveling below $55 \mathrm{mph}$.

Furthermore, while the field data showed that only $0.14 \%$ of the observed vehicles were traveling with speeds below $40 \mathrm{mph}$ (the posted minimum speed limit) averaged across all sites, analysis of crash data revealed that about $9 \%$ of vehicles were involved in the crashes with 
Figure 2: Distributions of Estimated Speeds Prior to Crash and Speeds of Actual Vehicles at the Site

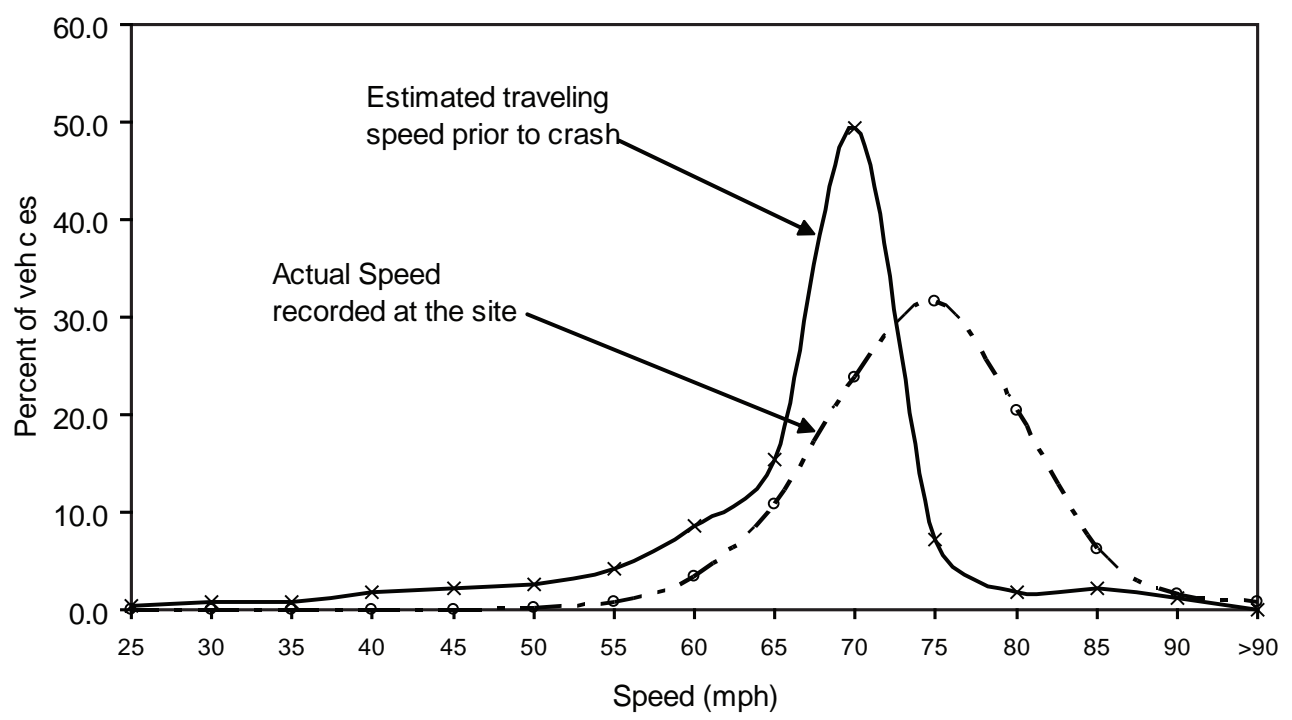

estimated speeds below $40 \mathrm{mph}$. This analysis suggests that slow driving is dangerous and poses a bigger risk of crashing even when the proportion of slow moving vehicles in the traffic stream on these freeway sections is low.

\section{MODELING CRASHES}

\section{Vehicle Speeds and Crash Involvement Rates}

Previous research indicates that the deviation of vehicle travel speeds from the mean speed is correlated to crash involvement rates. Unlike frequency of crashes, the crash involvement rate accounts for the effect of vehicle miles of travel (a product of traffic volume and the distance the vehicles traveled) on occurrence of the crash. The crash involvement rate is the ratio of the number of crashes that occurred in a specified speed range, $S_{i}$, to the total number of vehicle miles traveled in that speed range, i.e.,
The vehicle travel speeds were expressed as the deviations from the average speed of traffic obtained from the operational data. It is worth noting that the analysis of actual speed data collected across these sites revealed that the average speed of traffic on these highways was $73 \mathrm{mph}$. Table 2 shows the speed deviations from the average speed of vehicles in the field and their corresponding crash involvement rates. The scatter plot (Figure 3) of the involvement rate versus speed deviation showed that higher negative speed deviations had higher involvement rates. This necessitated the use of logarithmic transformation of the vehicle involvement rates as shown in the third column of Table 2.

The scatter plot depicted in Figure 3 suggested a curvilinear relationship between crash involvement rates and speed deviations. Visual inspection of Figure 3 indicates that a second order polynomial regression model is most appropriate for fitting the crash

(1) Crash Involvement Rate $=\frac{\text { Number of crashes occuring within speed range } S_{i}}{\text { Total vehicle miles of travel within speed range } S_{i}}$ 
Table 2: Crash Involvement Rates versus Deviation of Speed from the Mean Speed

\begin{tabular}{|c|c|c|}
\hline $\begin{array}{c}\text { Speed Deviation, SD } \\
(\mathbf{m p h})\end{array}$ & $\begin{array}{c}\text { Crash Involvement Rate, CIR (Crashes/Mil- } \\
\text { lion vehicle miles) }\end{array}$ & logCIR \\
\hline-30 & 30000 & 10.31 \\
\hline-25 & 6494 & 8.78 \\
\hline-20 & 2885 & 7.97 \\
\hline-15 & 1215 & 7.10 \\
\hline-10 & 769 & 6.64 \\
\hline-5 & 497 & 6.21 \\
\hline 0 & 914 & 6.82 \\
\hline 5 & 134 & 4.90 \\
\hline 10 & 123 & 4.81 \\
\hline 15 & 413 & 6.02 \\
\hline 20 & 580 & 6.36 \\
\hline
\end{tabular}

involvement rates. Therefore, the dependent variable which measures the risk of the vehicle being involved in a crash was modeled in this form $\log C I R=\beta_{o}+\beta_{1} S D+\beta_{2} S D^{2}+\varepsilon$

\section{(2)}

where $\beta_{i}$ are the regression coefficients which are determined by the model, $S D$ is the deviation from average speed, and $\varepsilon$ is the error term for uncorrelated variables with the mean of zero and a constant variance. The data were modeled by linear regression after creating a second independent variable as the square of the deviation from the mean speed. The regression results are presented in Table 3 . The fitted curve is also presented in Figure 3.

The quality of the fitted model was evaluated by the coefficient of determination $\left(\mathrm{R}^{2}\right)$ and the $F$-statistic. From the model results presented in Table 3, a large value $(90 \%)$ of the $\mathrm{R}^{2}$ suggests that the second order polynomial model adequately fits the data which has significant curvature. In addition, the small $p$ value (0.0001) of the overall model obtained from the overall $F$-statistic indicates that the model is statistically significant. The partial $t$-tests for the individual coefficients in the model showed that they were all significant. Therefore, the risk of crash involvement took the following form:

(3) $\log ($ Crash Involvement Rate $)=$

$$
5.754-0.048 \mathrm{SD}+0.003 \mathrm{SD}^{2}
$$

The minimum risk of being involved in the crash was obtained by equating the first derivative of equation 3 to zero. The derivative of equation 3 is $-0.048+0.006 \mathrm{SD}$. When this derivative is set to zero the resulting solution is $\mathrm{SD}=8$ $\mathrm{mph}$. This result shows that the minimum risk is obtained when the traveling speed is about 8 mph above the average speed which translates to $81 \mathrm{mph}$ as the field data showed an average speed of $73 \mathrm{mph}$. This finding mirrors the results that were obtained by Solomon (1964) and Cirrilo (1968) who showed that the driving speed at the minimum risk of crashing is about 5-10 mph and $12 \mathrm{mph}$, respectively, above the average speed. Furthermore, the data show that the risk is higher when traveling at the average speed than traveling at $8 \mathrm{mph}$ above and below the average speed.

Table 3: Regression Results of the Polynomial Model

\begin{tabular}{|l|c|c|c|c|}
\hline & Coefficient, $\beta$ & Standard Error & $\mathbf{t}$ & $\boldsymbol{p}$-value \\
\hline Constant & 5.754 & 0.246 & 23.35 & 0.000 \\
\hline SD & -0.048 & 0.013 & -3.65 & 0.007 \\
\hline SD $^{2}$ & 0.003 & 0.001 & 4.33 & 0.003 \\
\hline
\end{tabular}

$F=38.15$, Prob $>F=0.0001, R^{2}=0.905$ 
Figure 3: Crash Involvement Rate versus Deviation from the Mean Speed of Traffic Stream

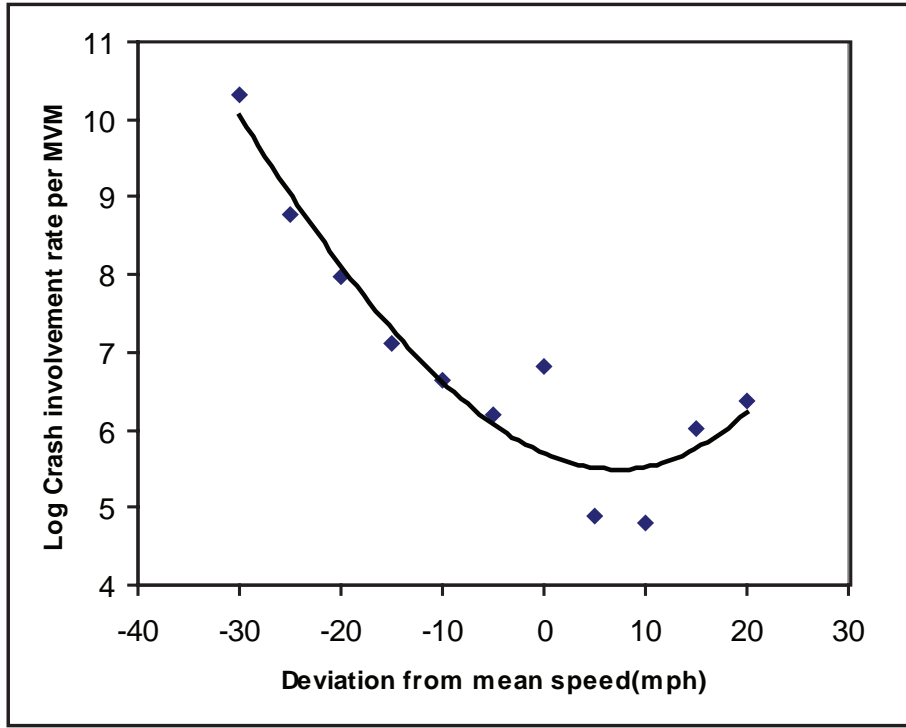

Another issue worth noting from the polynomial model developed in this analysis is that correlation of the speed distribution and risk of crash involvement revealed that the minimum risk is equivalent to the $85^{\text {th }}$ percentile speed of the speed distribution observed on these highways. These findings mirror the recommendation made by one FHWA study (Parker 1985) that the minimum and maximum speed limits should be set at $10 \mathrm{mph}$ below and above the average speed, respectively. The Parker (1985) study suggested that the speed that is $10 \mathrm{mph}$ below the average represented the $10^{\text {th }}$ percentile while the speed that is 10 mph above the average represented the $90^{\text {th }}$ percentile.

\section{Poisson Regression}

The Poisson regression model was used to test hypotheses on the effect of speed characteristics recorded from the sites on the frequency of crashes. The analysis assumed that the crashes occurring on these freeway sections follow a count distribution-a distribution that refers to a simple enumeration of events. The theory behind this assumption was that crashes occurring on these highway sections were rare and countable events occurred independently. A generalized log-linear model was then used to fit the data to the Poisson distribution. The procedure used was to model crash counts as the exponential function of the independent variables. The generalized crash model took the following form:

(4) $\lambda=e^{\beta_{i} x_{i}}+\varepsilon$

where $\lambda$ is the mean number of crashes and $x_{i}$ 's are the vectors of geometric and traffic variables with coefficients $\beta$.'s which are estimated by the model. The parameter $\varepsilon$ is the error term for uncorrelated random variables and intrinsic randomness whose variance increases as the mean increases. This model is estimated by the method of maximum likelihood. The significance of the estimated parameters is tested by the asymptotic normality of maximum likelihood estimates. The model evaluation is performed by assessing the goodness-of-fit using the scaled deviance statistic.

Four log-linear models were tested in this study. The models were differentiated by the dependent variable, i.e., the total number of crashes, the number of fatal crashes, the number of injury crashes, and the number of property damage only crashes. The number of crashes was used as a dependent variable instead of the crash rate to avoid confounding the effect of traffic volume on occurance of crashes. Selection of independent variables in the modeling was focused on the speed variables that would 
directly or indirectly show the contribution of low end speed distribution and speed variations to traffic crashes. These variables were the median speed, the $15^{\text {th }}$ percentile speed, and the difference between the $85^{\text {th }}$ and the $15^{\text {th }}$ percentile speed. The difference between the $85^{\text {th }}$ and $15^{\text {th }}$ percentile speed was used as a proxy for the speed variation. In addition, the percent of vehicles traveling below $60 \mathrm{mph}$ was included as a variable to represent the amount of traffic traveling at the lower end of the speed distribution. The inclusion of traffic volume as an independent variable in the model was inspired by the results of prior research which revealed that traffic volume and crashes vary in a nonlinear function (Hall and Pendleton 1990). From the discussion of the previous section, it was expected that the larger the $15^{\text {th }}$ percentile speed and the median speed the less likely the vehicles are to be involved in a crash on the roadway, i.e, a negative sign. Because the $85^{\text {th }}-15^{\text {th }}$ percentile difference is the measure of speed variations between the fast and slowmoving vehicles, the larger the difference the more interaction occurs between vehicles and the more likely the vehicles would be involved in a crash, i.e, a positive sign. It was also expected that volume will have a positive sign because as traffic increases the number of traffic crashes increase.

\section{Results of the Parameter Estimates}

The calculation of the scaled deviance resulted in a value equal to one, confirming that the assumption of Poisson distribution was appropriate. The results of the parameter estimates are presented in Table 4. The results for total crashes, fatality, and injuries models show that all covariates were very significant $(p \leq 0.0001)$ in influencing crash occurrence. All variables included in the models, except the median speed, had a positive sign. Closer examination of the parameter estimates of the total crashes, fatality and injuries models revealed the following outcomes. The estimated coefficients for volume, the $15^{\text {th }}$ percentile speed, the percentage of vehicles traveling below $60 \mathrm{mph}$, and the percent difference between $85^{\text {th }}$ and $15^{\text {th }}$ percentile speeds were positive and statistically significant, implying that as the values of these variables increase the frequency of crashes also increases. However, the frequency of crashes was found to decrease with the increase of the median speed. The results presented in Table 4 further show that the frequency of fatal and injury crashes increased significantly as the volume of traffic, the $15^{\text {th }}$ percentile speed, the percent of vehicles with speed below $60 \mathrm{mph}$, and the difference between $85^{\text {th }}$ and $15^{\text {th }}$ percentile speeds increased. However, the increase of the median speed was found to significantly decrease the likelihood of fatal crashes.

For the property-damage-only crashes, the model results showed that the median speed significantly decreases the frequency of property-damage-only crashes while the traffic volume, the $15^{\text {th }}$ percentile speed, and the $85^{\text {th }}-15^{\text {th }}$ percentile difference significantly increase the likelihood of property damage crashes. However, the percent of vehicles traveling with speed below $60 \mathrm{mph}$ was negative but statistically insignificant ( $p=$ 0.8880 ). The negative sign of the percent of vehicles traveling with speed below $60 \mathrm{mph}$ was unexpected because, intuitively, increasing this variable may increase speed variations and hence increase property damage crashes. Therefore, the property-damage-only model was reanalyzed without this variable. Elimination of the percent traveling below $60 \mathrm{mph}$ reduced the model errors and hence raised the partial chi-square values making all independent variables significant with $p$-values of less than 0.0001 (Table 5). The effect of median speed on PDO crashes was negative, while the effects of volume, $15^{\text {th }}$ percentile speed and $85^{\text {th }}-15^{\text {th }}$ percentile difference were positive.

The modeling exercise discussed above shows some mixed results in interpreting the overall effect of the speed distribution on crash involvement on rural interstate highways in Florida. A constant theme in all four models is that as the $15^{\text {th }}$ percentile speed increases, the frequency of all crashes (regardless of severity level) increases. This seems counterintuitive since operationally as the $15^{\text {th }}$ percentile speed increases, speeds become more uniform thus reducing conflicts caused by speed variability. One can speculate that the drivers whose speeds are at the lower end of the speed distribution are not regular commuters who mostly choose to 
Table 4: Poisson Regression Parameter Estimates

\begin{tabular}{|c|c|c|c|c|}
\hline Model & Variable & Coefficient & $\chi^{2}$ & $p$-value \\
\hline \multirow{6}{*}{ Total crashes } & Intercept & -7.7461 & 32.86 & $<.0001$ \\
\hline & Median & -1.8648 & 848.82 & $<.0001$ \\
\hline & Volume & 0.000055 & 2860.75 & $<.0001$ \\
\hline & $15^{\text {th }}$ Percentile & 2.0844 & 746.63 & $<.0001$ \\
\hline & $\%$ below $60 \mathrm{MPH}$ & 29.4506 & 235.77 & $<.0001$ \\
\hline & $85^{\text {th }}-15^{\text {th }}$ percentile & 0.5113 & 829.37 & $<.0001$ \\
\hline \multirow{6}{*}{ Fatality } & Intercept & -1408.76 & $7.63 \mathrm{E} 12$ & $<.0001$ \\
\hline & Median & -31.5887 & 5.53E13 & $<.0001$ \\
\hline & Volume & 0.0011 & $1.26 \mathrm{E} 13$ & $<.0001$ \\
\hline & $15^{\text {th }}$ Percentile & 53.2955 & $2.23 \mathrm{E} 13$ & $<.0001$ \\
\hline & $\%$ below $60 \mathrm{MPH}$ & 2016.463 & $9.08 \mathrm{E} 12$ & $<.0001$ \\
\hline & $85^{\text {th }}-15^{\text {th }}$ percentile & 6.3620 & $7.63 \mathrm{E} 12$ & $<.0001$ \\
\hline \multirow{6}{*}{ Injuries } & Intercept & -18.8898 & 2.56 & 0.1093 \\
\hline & Median & -1.7713 & 10.15 & 0.0014 \\
\hline & Volume & 0.0001 & 33.49 & $<.0001$ \\
\hline & $15^{\text {th }}$ Percentile & 2.1444 & 10.57 & 0.0012 \\
\hline & $\%$ below $60 \mathrm{MPH}$ & 41.0773 & 6.01 & 0.0142 \\
\hline & $85^{\text {th }}-15^{\text {th }}$ percentile & 0.4712 & 9.34 & 0.0022 \\
\hline \multirow{6}{*}{ PDOs } & Intercept & 19.4417 & 1.66 & 0.1974 \\
\hline & Median & -1.9239 & 7.27 & 0.0070 \\
\hline & Volume & 0.0001 & 25.28 & $<.0001$ \\
\hline & $15^{\text {th }}$ Percentile & 1.7256 & 4.07 & 0.0436 \\
\hline & $\%$ below $60 \mathrm{MPH}$ & -2.9454 & 0.02 & 0.8886 \\
\hline & $85^{\text {th }}-15^{\text {th }}$ percentile & 0.5884 & 8.68 & 0.0032 \\
\hline
\end{tabular}

Table 5: Revised Property Damage Crashes Model

\begin{tabular}{|l|l|c|c|c|}
\hline Model & Variable & Coefficient & $\chi^{2}$ & p-value \\
\hline \multirow{4}{*}{ PDO } & Intercept & 17.4261 & 27.36 & $<.0001$ \\
\cline { 2 - 5 } & Median & -1.8648 & 34.6 & $<.0001$ \\
\cline { 2 - 5 } & Volume & 0.0001 & 38.17 & $<.0001$ \\
\cline { 2 - 5 } & $15^{\text {th }}$ Percentile & 1.8147 & 29.48 & $<.0001$ \\
\cline { 2 - 5 } & $8^{\text {th }}-15^{\text {th }}$ percentile & 0.5979 & 25.6 & $<.0001$ \\
\hline
\end{tabular}


travel slow relative to the regular commuters. These inexperienced drivers are more likely to be involved in crashes. Also, older drivers may choose to drive slow because of their slower reaction times or reduced visual capabilities.

\section{CONCLUSION}

This paper presented the results of an operational and safety review of the Florida interstate freeway system in relation to the minimum speed limit. The field data on speed and traffic volume were reviewed in conjunction with historical crash data. The approach used in the research was to correlate speed characteristics with reported crashes while attempting to quantify the level of importance that various speed characteristics had on safety of operations on the selected rural freeway sections.

The operational analysis showed that $57 \%$ of the recorded vehicles exceeded the posted maximum speed limit of $70 \mathrm{mph}$ while only $0.14 \%$ of the vehicles had speeds below the posted minimum speed limit of $40 \mathrm{mph}$. The $85^{\text {th }}$ and $15^{\text {th }}$ percentile speeds, which some of the literature suggested should be used as a guide in setting maximum and minimum speed limits were $80 \mathrm{mph}$ and $65 \mathrm{mph}$, respectively. A combined analysis of speed and crash data revealed that while only $0.14 \%$ of the vehicles had field-recorded speeds below 40 mph, $9 \%$ of the crash-involved vehicles were estimated to have speeds below $40 \mathrm{mph}$. The overrepresentation of slow vehicles in the crashes shows that even a few vehicles with speed characteristics unlike the mainstream can cause deterioration of safety of travel on highways. This result may underscore the need to raise minimum speeds.

The safety modeling results indicate that speed variation increases the frequency of crashes. Thus, measures to reduce the difference between fast and slow-moving vehicles could improve the overall safety of operation of these highways sections. Furthermore, the model results indicate that the presence of a significant amount of vehicles traveling less than $60 \mathrm{mph}$ increases the likelihood of crashes. This calls for the need to restrict the number of vehicles driving slowly relative to the mean speed of the traffic stream. The second order polynomial model developed showed that the risk of being in a crash is parabolically related to the speed deviation with the minimum risk occurring when vehicles were traveling at 81 $\mathrm{mph}$, which is $8 \mathrm{mph}$ above the mean speed. The $81 \mathrm{mph}$ speed was equivalent to the $85^{\text {th }}$ percentile speed observed in the field. Should the minimum speed be raised to $65 \mathrm{mph}$ which is equivalent to the $15^{\text {th }}$ percentile of operating speeds observed in the field? Further research is needed to answer this question but it can be presumed that higher minimum speed might increase incidents of driver error particularly for vulnerable drivers - e.g., older drivers, recreational vehicle drivers, drivers of vehicles towing trailers, and not regular commuters who are probably comfortable with speeds below 65 mph but above $40 \mathrm{mph}$. These drivers are likely to be involved in the crash.

It should be noted that additional work is needed to increase the confidence in the results reported herein. First, the use of police reported pre-crash speed as the representative operating speed prior to crash in the analysis could lead to skewed results. While this work assumed a correlation between the two speeds, future work should attempt to determine actual pre-crash speed. Second, a detailed study is desirable in which operational and safety data on sites with minimum posted speed are compared to those without minimum posted speed. The survey study conducted by Mussa (2003) indicated that 25 states do not post minimum speed limit signs on interstate highways. Thus, a multistate study is recommended. Third, the safety modeling discussed above would benefit from additional sample size of the study sites that would enable other covariates such as the number of lanes, time of day, and driver's familiarity with the road to be incorporated in the model. 


\section{References}

Cirillo, J. A. “Interstate System Accident Research Study II, Interim Report II.” Public Roads 35(1), (1968):71-76.

Florida Department of Transportation (FDOT). Speed Zoning for Highways, Roads and Streets in Florida. FDOT Manual No. 750-010-002, 1997.

Garber, N. and A. Ehrhert. The Effect of Speed, Flow, and Geometric Characteristics on Crash Rates for Different Types of Virginia Highways. Virginia Transportation Research Council, Charlottesville, Virginia, 2000.

Garber, N. and Gadiraju, R. Factors Affecting Speed Variance and its Influence on Accidents. University of Virginia, Charlottesville, Virginia. Prepared for AAA Foundation for Traffic Safety, Washington, D.C., 1998.

Hall, J. and O. Pendleton. "Rural Accident Variation with Traffic Volume." Transportation Research Record: Journal of the Transportation Research Board 1281, (1990): 62-70.

Harkey, D.L., D. H. Robertson, and S. E. Davis. “Assessment of Current Speed Zoning Criteria.” Transportation Research Record: Journal of the Transportation Research Board 1281, (1990): 40-51.

Hauer, E. “Accidents, Overtaking, and Speed Control.” Accident Analysis and Prevention 3, (1971): 1-13.

Lave, C. "Speeding, Coordination, and the 55 MPH Limit.” American Economic Review 75, (1985): 1159-1164.

McShane, W. R., R. P. Roess, and E. S. Prass. Traffic Engineering. Prentice-Hall, Upper Saddle River, New Jersey, 1998.

Mussa, R. Nationwide Survey of the Practice of Posting Minimum Speed Limit Signs on Interstate Freeways. Report by FAMU-FSU College of Engineering for the Florida Department of Transportation, Tallahassee, Florida, 2003.

Parker, M.R. Jr., Synthesis of Speed Zoning Practices. Publication FHWA/RD-85/096, FHWA, U.S. Department of Transportation, Washington, D.C., 1985.

Solomon, D. Accidents on Main Rural Highways Related to Speed, Driver and Vehicle. Bureau of Public Roads, U.S. Department of Commerce, Washington, D.C., 1964.

Transportation Research Board (TRB). Special Report 204: 55 A Decade of Experience. National Research Council, Washington, D.C., 1984.

U.S. Department of Transportation (USDOT), Federal Highway Administration. Highway Capacity Manual. Washington, D.C., 2000.

West, L.B. and J. W. Dunn. “Accidents, Speed Deviation and Speed Limits.” Traffic Engineering 41(10), (1971): 52-55. 
$\overline{\text { Mr. Victor Muchuruza is a Ph.D. student at Florida State University. He has been involved in }}$ a research project entitled "Evaluate the Relevance of Minimum Speed Limit on Rural Interstate Freeways." His research interests include simulation and modeling of highway traffic operations and safety. He also performs research on stochastic modeling of traffic conflict and crashes using numerical simulation.

Dr. Renatus Mussa is an associate professor and director of the Traffic Engineering Laboratory at the FAMU-FSU College of Engineering. Dr. Mussa has been teaching with the Department of Civil and Environmental Engineering of the FAMU-FSU College of Engineering since 1998. He has conducted research in different areas of transportation engineering including intelligent transportation systems, highway safety, and traffic studies. 